Motrivivência $\quad$ v. 26, n. $42, \quad$ P. 250-258, junho/2014

http://dx.doi.org/10.5007/2175-8042.2014v26n42p250

\title{
REFLEXÕES ACERCAA DA DISPONIBILIZAÇÃO DE FONTES HISTÓRICAS NO CEMEDEF/UFPR
}

\author{
Kauê Fabiano da S. Queiroz \\ Paola Caroline Silva Azevedo? \\ Tiago Dimitrow Zanlorenzi ${ }^{3}$ \\ André Mendes Capraro 4 \\ Marcelo Moraes e Silva ${ }^{5}$ \\ Fernando Marinho Mezzadrib \\ Letícia Godoy?
}

\section{RESUMO}

Apresenta-se no presente texto uma reflexão sobre a disponibilização de fontes históricas realizadas no Centro de Memória do Departamento de Educação Física da Universidade Federal do Paraná. Norteada pelas seguintes questões: quando tornar acessível? Como tornar acessível? Para quem tornar acessível? O trabalho buscou refletir a respeito do papel desses centros na guarda da memória e na fomentação de pesquisas. A conclusão geral é que apesar de tais instituições serem fundamentais para o fomento à pesquisa nas áreas de Ciências Sociais o esforço realizado no presente caso foi "limitado" e "limitante", porém feito sem ficção, alarde e com todos os cuidados que a vida cotidiana impõe a quem realiza pesquisa histórica em Educação Física no Brasil.

Palavras-Chave: Centro de Memória; Educação Física; Fontes Históricas.

1 Graduado em Lic. Educação Física. UFPR, Curitiba/Paraná, Brasil.

E-mail: moraes_marc@yahoo.com.br

2 Graduado em Lic. Educação Física. UFPR, Curitiba/Paraná, Brasil.

E-mail: moraes_marc@yahoo.com.br

3 Graduado em Lic. Educação Física. UFPR, Curitiba/Paraná, Brasil.

E-mail: moraes_marc@yahoo.com.br

4 Doutor em História. UFPR, Curitiba/Paraná, Brasil.

E-mail: andrecapraro@onda.com.br

5 Pós-Doutorando em Educação Física. UFPR, Curitiba, Paraná, Brasil.

E-mail: moraes_marc@yahoo.com.br

6 Doutor em Educação Física. UFPR, Curitiba/Paraná, Brasil.

E-mail: fmezzadri@uol.com.br

7 Doutora em Educação Física UNICAMP. Professora do curso de Educação Física/UFPR, Curitiba/Paraná, Brasil. E-mail: leticiagodoy@uol.com.br 


\section{INTRODUÇÃO ${ }^{8}$}

O Centro de Memória do Departamento de Educação Física da UFPR - CEMEDEF/UFPR é responsável pela organização e disponibilização do acervo de livros pertencente à biblioteca da antiga Escola de Educação Física e Desportos do Paraná (1941-1977). Tal Instituição foi fundada no início do ano de 1941, na cidade de Curitiba. Sua fundação, em caráter particular, foi motivada pela necessidade crescente de formação de professores de Educação Física para o exercício do ofício em clubes e escolas de todo o Estado do Paraná. Posteriormente, no ano de 1977, a Escola de Educação Física e Desportos do Paraná foi incorporada à Universidade Federal do Paraná (UFPR) . (MORO E GODOY, 2006; ALVES DE SOUZA E CAPRARO, 2010; 2013).

O CEMEDEF/UFPR - foi criado no ano de 2004, com o compromisso de desempenhar um papel integrador entre o mundo acadêmico e a comunidade, através das atividades propostas na relação ensino, pesquisa e extensão. O acervo possui aproximadamente 700 obras e itens, entre livros, periódicos, manuais, boletins, revistas, monografias, artigos, coletâneas, atas, correspondências, ofícios, fontes iconográficas e demais documentos burocráticos. Esse rico acervo de fontes históricas era considerado um arquivo morto pelo sistema de bibliotecas da UFPR e, consequentemente, encontrava-se esquecido em uma sala do Departamento de Educação Física. (MORO E GODOY, 2006; ALVES DE SOUZA E CAPRARO, 2010; 2013).

Hoje, a organização do acervo é prioridade da disciplina Projetos Integrados do curso de Licenciatura em Educação Física. Os alunos matriculados nesta matéria realizam a classificação das obras por meio de uma ficha elaborada pela equipe do Centro de Memória ${ }^{10}$ e, na sequência, inserem essas informações em um banco de dados ${ }^{11}$, com o objetivo localizar, mapear, reunir, catalogar essas fontes como suporte para programas de pesquisa, suscitando novas possibilidades de temáticas e objetos de estudo. Assim, este trabalho tem por objetivo fazer uma reflexão sobre a experiência realizada no CEMEDEF/UFPR.

Observa-se, portanto, que as tensões geradas pelas relações entre pesquisa, arquivamento e disponibilização, bem como suas interfaces com diferentes áreas do conhecimento, são postas no dia-a-dia da organização dos acervos históricos; e, à medida que surgem novos problemas (questões inéditas e/ou especificidades), muitas vezes, não se tem respostas ou soluções

8 A presente temática teve como ponto de partida a discussão na mesa presidida pela professora Dr. Gisele de Souza, no II Encontro de Arquivos Escolares e Museus Escolares, na Universidade Federal do Paraná, em abril de 2008, e, sobretudo, em face das tensões vividas dia-a-dia no CEMEDEF/UFPR. (MORO E GODOY, 2006; ALVES DE SOUZA E CAPRARO, 2010).

9 Mais detalhes sobre a referida instituição consultar artigo de autoria de Moraes e Silva e Capraro (2011).

10 A equipe do CEMEDEF/UFPR conta com a presença de cinco professores do curso de Educação Física, que coordenam o trabalho dos graduandos do curso de Educação Física. O detalhamento das fichas de catalogação pode ser encontarda no texto de Moro e Godoy (2006).

11 O arquivamento no banco de dados está sendo feito a partir de padrões internacionais seguindo as normas do ISAAD(G) - Norma Geral Internacional de Descrição Arquivística (2000) e ISAAR (CPF) (1998) - Norma Internacional de Registro de Autoridade Arquivística para Entidades Coletivas, Pessoas e Famílias. Mais detalhes técnicos sobre a construção do banco de dados e os campos que o compõem consultar texto de Moro e Godoy (2006). 
imediatas. Entretanto, assim como afirma Bloch (2001), ao tematizar sobre ofício do historiador, é necessário que os indivíduos que realizam pesquisas históricas cruzem novas fronteiras, inclusive teóricas e disciplinares, para poder desvendar as dúvidas e produzir um conhecimento histórico mais consistente. Baseados na reflexão do historiador francês parte-se, primariamente, da seguinte premissa para o objeto de nossa ação: o CEMEDEF/UFPR tem como um dos seus objetivos básicos recuperar, preservar e divulgar a memória da Educação Física do Estado do Paraná, fomentando a produção científica no campo da pesquisa histórica em Educação Física no país. Este objetivo é baseado em dois compromissos comuns aos Centros de Memória e Arquivamento: a preservação de documentos e a fomentação de pesquisas nos mais diversos níveis.

Norteados por essas duas máximas, entende-se que a presente discussão se faz necessária para estabelecer diálogos futuros com outros Centros de Memória de Educação Física existentes em outras universidades do país e, sobretudo, para refletir sobre como os pontos acima citados podem ser enfrentados, a partir de um relato de experiência. (MAZO, 2001; GOELLNER, 2003; MELO, 2005; ROSA et. al. 2008).

Neste sentido, o desenvolvimento do trabalho está pautado em três questões norteadoras: quando tornar acessível? Como tornar acessível? Para quem tornar acessível? E, em última instância, qual o papel dos Centros de Memória de Educação Física, Esporte e Lazer?

\section{Quando tornar acessível?}

A questão sobre quando tornar o acervo dos Centros de Memória acessível surge na primeira relação com as fontes, ou seja, na etapa de recuperação, de restauração e de organização. Grande parte do acervo, hoje pertencente ao CEMEDEF/ UFPR, outrora era considerado um arquivo morto, depositado em uma sala sem as mínimas condições de preservação ou apreço reativos a essa memória. (MORO E GODOY, 2006; ALVES DE SOUZA, 2010; 2013). Nesse sentido, concorda-se, portanto, com a afirmativa de que... "Não basta limpar, inventar e organizar, é também fundamental reinstalar a informação a partir de uma nova organização" (MAGALHÃES, 1999 , p. 59). Goellner amplia tal discussão no seguinte trecho.

[...] centros de memória e de documentação, na medida em que sua intervenção política se destinar não apenas a agrupar dados, objetos, documentos, experiências individuais e coletivas mas, fundamentalmente, preservar e transmitir informações oriundas de suas coleções às novas gerações, por entender que ali alojam-se conhecimentos de grande significação social (GOELLNER, 2003, p. 200).

A partir dessa nova gestão, desse novo sentido que é dado ao acervo, os quais por si só são uma maneira de fazer história, ricas possibilidades de investigação histórica são lapidadas. A tensão, via de regra gerada nesse momento, ocorre quando o historiador/arquivista ${ }^{12}$ percebe

12 Nesse momento, articulados os ofícios de historiador/arquivista, pois a realidade do CEMEDEF/UFPR pode ser compartilhada com outros Centros de Memória: o pesquisador também exerce a função de arquivista. 
a importância das fontes que tem em mãos e o seu péssimo estado de conservação, o qual muitas vezes não permite o manuseio para pesquisa sem uma restauração prévia; ou, ainda, quando é necessária a organização de toda a documentação para , enfim, disponibilizá-la. Inclusive, algumas vezes a necessidade da restauração e organização das fontes pelo arquivista, bem como a exigência de manuseio das mesmas pelo pesquisador, surgem de forma concomitante. Alves de Souza e Capraro (2010, p.4-5), no trecho reproduzido abaixo resumem como se deu o inicio dos trabalhos do CEMEDEF/UFPR:

Em se tratando de estrutura, inicialmente foi perfilada toda a demanda resultante da doação, em seguida, a missão foi separá-la cronologicamente e por especificidade. A atuação de discentes voluntários foi essencial para dar rumo ao projeto que decorreria. $\mathrm{O}$ corpus não apresentava degradação que comprometesse sua validade, porém estava abrigado em locais bastante inapropriados. Procurou-se o Arquivo Público Paranaense para se preludiar os protocolos e normas necessárias, a fim de que todo o acervo pudesse ser inventariado. Tomou-se o cuidado de seguir as determinações, justamente para não comprometer os elos que vinculavam uma fonte à outra. É importante saber dessas relações, pois para descrever um documento, torna-se parte do processo elucidara proveniência. Por exemplo, se pertence ao um conjunto maior, pois o entendimento de um documento fora do seu contexto fica comprometido. Indispensável ainda é a compreensão de toda a carga orgânica que foi transferida na produção do documento e qual sentido buscava contemplar o produtor.

Como Alves de Souza e Capraro (2010), lembram, no primeiro momento, as atividades do CEMEDEF/UFPR em relação ao acervo priorizaram o trabalho técnico, com o foco no arquivamento dos conteú$\operatorname{dos}^{13}$. A tarefa de organizar 700 obras com diversas peculiaridades foi e ainda é um grande desafio para a equipe do CEMEDEF/ UFPR. A ficha de catalogação dessas obras levou um ano e meio até chegar a sua versão definitiva, tentando atender as necessidades desse acervo, procurou sempre valorizar o conjunto geral de informações ${ }^{14}$.

Outro ponto fundamental neste tópico é o relativo ao estado de conservação das obras: algumas surpreendentemente bem conservadas; outras, em estado deplorável. As condições do acervo, tanto na parte de preservação, quanto no tangente à organização, obrigou a equipe do CEMEDEF/ UFPR a limitar o acesso às obras. Entretanto, era notória a necessidade de consulta ao acervo para pesquisa por parte dos alunos de graduação do curso de Educação Física,

13 O acervo é composto da seguinte tipologia de fontes: 1) Arquivo da antiga Escola de Educação Física; 2) Arquivo com as pastas pessoais dos professores; 3) Arquivo do Centro Acadêmico de Educação Física; 4) Bibliografias Antigas. Atualmente todo o acervo se encontra inventariado conforme as recomendações técnicas para arquivamento (Nobrade). Sobre o detalhamento da tipologia de fontes que compõem o acervo consultar Alves de Souza e Capraro (2010).

14 Como a forma e o modo como se deu a constituição do arquivo do CEMEDEF/UFPR não é foco do presente artigo o mesmo não será explorado no texto em questão. Por isso questões sobre o detalhamento da ficha de catalogação e a forma de armazenamento no banco de dados relativos ao CEMEDEF/UFPR podem ser visualizados com riqueza de detalhes nos trabalhos publicados anteriormente por Moro e Godoy (2006) e Alves de Souza e Capraro $(2010 ; 2013)$. 
dos mestrandos em Educação Física da UFPR, dos professores do curso de Educação Física, bem como dos alunos de outras instituições de ensino superior de Curitiba.

Diante das necessidades postas, é perceptível que é dever do Centro de Memória disponibilizar suas fontes, tanto quanto recuperar e organizar seu acervo. Apresenta-se, igualmente, esse problema pertinente e comum. $\mathrm{E}$, a partir do momento em que se reconhece que a necessidade de acessibilidade ao acervo se faz necessária de modo concomitante a sua organização (que, por sinal, é constante, pois não se podem privar os pesquisadores do acesso à documentação que, muitas vezes, é fundamental para pesquisa), é necessário apontar para outra questão...

\section{Como tornar acessível?}

Ainda focado no acervo de obras do CEMEDEF/UFPR, constata-se que os objetivos futuros (de implementação) em termos de acessibilidade são: inserção das informações no banco de dados; realização de uma parceria com o sistema de bibliotecas da UFPR, para a restauração de todas as obras, bem como sua disponibilização para consulta no próprio Departamento de Educação Física da UFPR; e, ainda, a veiculação do banco de dados a uma página deste Centro de Memória na internet. (MORO E GODOY, 2006; ALVES DE SOUZA E CAPRARO, 2010; 2013).

Louváveis por si só, as iniciativas, que não são exclusivas, mas realizadas (e já realidades) em outros Centros de Memórias, não contemplam outra questão presente: como tornar acessível o acervo antes das iniciativas se concretizarem no CEMEDEF/UFPR?
Para atender a esta necessidade, o CEMEDEF/UFPR adotou um critério próprio de disponibilizar o acervo para pesquisa e consulta. Qualquer pessoa só teria acesso com a presença dos professores coordenadores e/ou dos bolsistas. Todo pesquisador, seja graduando, pós-graduando ou professor, pode consultar o acervo, desde que faça contato prévio com a equipe do CEMEDEF/ UFPR e agende um horário. Tal iniciativa, apesar de não ser a ideal, foi entendida como a "melhor" solução (embora provisória) para atender a comunidade acadêmica que necessita das fontes, sem comprometer a integridade delas, e ainda respeitando a limitação da equipe do Centro de Memória, tendo em vista seu reduzido número de integrantes, bem como a disponibilidade de horário dos mesmos. (ALVES DE SOUZA E CAPRARO, 2010; 2013).

Em última instância, ressalta-se que é fundamental estabelecer o diálogo com outras instituições de preservação da memória, pois é evidente que grandes acervos não são organizados em pouco tempo, sobretudo porque há a necessidade de um trabalho árduo e minucioso para não comprometer as fontes, o qual requer considerável espaço de tempo para disponibilizá-las de forma completa, em um sistema mais moderno e de fácil acesso.

\section{Para quem tornar acessível?}

Esta questão, tão pertinente nesse momento quanto as outras, parece de outra natureza. A discussão ganha significativa proporção quando se pensa que a limitação de acesso às fontes pode ocorrer porque coordenadores dos Centros de Memória, e seus orientandos, procuram resguardar o 
acervo para suas próprias pesquisas, limitando assim a outros pesquisadores o acesso a fontes mais "importantes" e/ou "inovadoras". Entretanto, é necessário lembrar que não existe fonte histórica mais importante do que outra, ou mais valiosa. Toda e qualquer fonte tem um significado e um valor, principalmente para a época a que pertenceu. "[...] as fontes só se manifestam diante das interrogações que a elas dirigimos; a qualidade dessas manifestações decorre da qualidade das nossas interrogações" (MENEZES, SILVA E TEIXEIRA, 2005, p. 68).

Goellner (2003) argumenta que os projetos fomentados pelos acervos dos Centros de Memória e pelos Museus Esportivos, devem ser disponibilizados para um número infinito de pessoas. Embora seja uma proposição admirável, nota-se que a realidade do CEMEDEF/UFPR não comporta tal iniciativa. As limitações físicas, de material, de recursos humanos e de recursos financeiros impedem a acessibilidade de seus acervos e projetos ao público em geral.

Se por um lado, é notório que a documentação não pode ficar restrita às equipes de Centros de Memórias, por outro, o acesso irrestrito e sem um regramento minucioso também é inviável, visto que poderia comprometer a integridade dos documentos lá existentes. Neste caso, existe a necessidade de encontrar um ponto de equilíbrio. Sob essa condição intermediária que o CEMEDEF/UFPR tem dirigido seus esforços.

Além de superar as dificuldades para permitir o acesso da comunidade acadêmica da própria UFPR - graduandos de Educação Física e de outros cursos, professores, funcionários, mestrandos e doutorandos - aos acervos, outras iniciativas merecem ser destacadas: a abertura do Centro de Memória para que alunos de outros cursos de Educação Física da cidade de Curitiba - Universidade Positivo (UP), Pontifícia Universidade Católica (PUC-PR), Universidade Tuiuti do Paraná (UTP) -, permitindo o contato com documentos históricos, bem como o desenvolvimento de pesquisas de cunho sócio-históricas; a realização da I Mostra do CEMEDEF/UFPR, na qual ocorreu a exposição dos acervos, materiais e pesquisas em desenvolvimento para a comunidade acadêmica e externa; e o planejamento de uma mostra fotográfica itinerante sobre a antiga Escola de Educação Física e Desportos do Paraná.

Nesse sentido, as ações do CEMEDEF/ UFPR buscam mesmo que a passos lentos ir organizando e com isso poder disponibilizar o acervo a um número cada vez maior de pessoas interessadas nas fontes que compõem o arquivo da instituição.

\section{CONSIDERAÇÕES FINAIS: o papel do CEMEDEF/UFPR}

A memória desafia o historiador para a explicação dessa mesma memória, representações e formas de conservação e de transmissão. (MAGALHÃES, 1999, p. 53).

Importante salientar que mesmo com todas as limitações e inconsistências encontradas pela equipe do CEMEDEF/ UFPR na condução do trabalho este foi o caminhado trilhado nesta árdua e dura tarefa de tentativa de preservação documental dos documentos iniciais duma das primeiras escolas de Educação Física em nível superior do Brasil. Esforço "limitado" e "limitante", porém feito sem ficção, alarde e com todos os cuidados que a vida cotidiana impõe a quem realiza pesquisa histórica em Educação Física no país. Tem a ciência que o 
mesmo hoje se encontra longe de ser um Centro de Memória na acepção que o termo merece, tratando-se no momento de um simples centro de arquivamento, mas que se configura como uma experiência singular feita como ensina Bloch (2001) na simplicidade que o oficio de historiador necessita.

Apesar das limitações a disponibilização dos documentos a cada semestre que passa acaba sendo ampliada, mesmo que a passos curtíssimos, pois são, em média, vinte alunos cursando a disciplina "Projetos Integrados", conjuntamente com a equipe de estagiários, que se revezam na distribuição das tarefas organizacionais. Sendo assim é inevitável, conforme apontaram Alves de Souza e Capraro $(2010 ; 2013)$ que o graduando ao permitir-se participar de um projeto que visa restabelecer a relevância da memória universitária, acabe por desenvolver afinidade com algum fato ou metodologia observada e, a partir delas, fomentar uma indagação de pesquisa histórica ${ }^{15}$.

A partir das questões abordadas, salienta-se o importante papel dos Centros de Memória, ou mesmo de um local de arquivamento, na preservação da memória e fomentação de pesquisas - um compromisso que, além do organizar e guardar documentos exige, acima de tudo, disponibilizar e tornar acessível, em tempo hábil, de forma adequada, para quem realmente necessite de uma documentação variada, cruzada, bem como ampliada para constituir uma pesquisa.

Este foi o objetivo traçado...

\section{REFERÊNCIAS}

ALVES DE SOUZA, E. ; CAPRARO, A. M. Preservando a memória, fazendo história: relato da fundação e das experiências desenvolvidas no Centro de Memória do Departamento de Educação Física da UFPR (CEMEDEF). Recorde: Revista de História do Esporte, v. 3, p. 1-16, 2010.

. A preservação da memória estudantil como proposta curricular dos cursos de Educação Física: o caso do centro de memória do Departamento de Educação Física (CEMEDEF) da UFPR. Movimento, Porto Alegre v. 19, n. 03, p. 235-255, jul/set de 2013.

CONSELHO INTERNACIONAL DE ARQUIVOS. ISAD(G): norma geral internacional de descrição arquivística. 2. ed. adotada pelo Comitê de Normas de Descrição, Estocolmo, Suécia, 1922 de setembro de 1999, versão final aprovada pelo CIA - Rio de Janeiro: Arquivo nacional, 2000.

CONSELHO INTERNACIONAL DE ARQUIVOS. COMISSÃO AD HOC DE DESCRIÇÃO. ISAAR (CPF): Norma internacional de registro de autoridade arquivística para entidades coletivas, pessoas e famílias. Rio de Janeiro: Arquivo Nacional, 1998.

GOELLNER，S. V. Informação e documentação em esporte, educação física e lazer: o papel pedagógico do centro de memória do esporte, Revista

15 Mais detalhes sobre o envolvimento discente e o CEMEDEF/UFPR consultar o artigo de Alves de Souza e Caparo (2013). 
brasileira de Ciências do Esporte, Campinas, v.25, n.1, p. 199-207, set.2003.

MAGALHÃES, J. Experiências de exploração do arquivo histórico de um liceu. In: FERNANDES, Rogério; MAGALHÃES, Justino (Org). Para a história do Ensino Liceal em Portugal: Actas dos Colóquios do I Centenário da Reforma de Jaime Moniz (1894-1895). Universidade do Minho, Braga, 1999. p. 51-61.

MAZO, J. Centro de Memória do Esporte da Escola de Educação Física da Universidade Federal do Rio Grande do Sul. Revista Brasileira de Ciências do Esporte, Campinas, v. 22, n.2, p. 155-166, 2001.

MELO, V. A. Centro de Memória Inezil Penna Marinho/EEFD/UFRJ: avanços e desafios. In: II Congresso do Centro de Memória da Educação Física, 2005, Belo Horizonte. II Congresso do Centro de Memória da Educação Física. Belo Horizonte: UFMg, 2005. v. 1.

MENEZES, M. C.; SILVA, E. C. L. da; TEIXEIRA JÚNIOR, O. O arquivo escolar: lugar de memória, lugar de história, Horizonte, v.23, n.1, p.67-76, jan./jun. 2005.

MORAES E SILVA, M.; CAPRARO, A. M.

$O$ contexto de fundação da Escola de Educação Física e Desportos do
Paraná: educando corpos para a vida urbana. Revista Brasileira de Ciências do Esporte, Florianópolis, v. 33, p. 623636, 2011.

MORO, V. L.; GODOY, L. Centros de memória em educação física, esporte e lazer: algumas contribuições para o debate. In: MEZZADRI, Fernando M.; CAVICHIOLLI, Fernando R.; SOUZA, Doralice L (orgs.). Esporte e lazer: subsídios para o desenvolvimento e a gestão de políticas públicas. Jundiaí, SP: Fontoura, 2006. p.117-130

ROSA, M. C. ; CUNHA, L. B. da ; JESUS, L. J. de . Centro de Memória da Educação Física, do Esporte e do Lazer: Constituindo a Coleção Professores. In: V Congresso Brasileiro de História da Educação, 2008, Aracaju. V Congresso Brasileiro de História da Educação, 2008.

VON SIMSON, O. R. de M. Memória, cultura e poder na sociedade do esquecimento: o exemplo do Centro de Memória da Unicamp. In: FARIA FILHO, L. M. (org.). Arquivos, fontes e novas tecnologias: questões pra a história da educação. Campinas: Autores Associados; Bragança Paulista: Universidade São Francisco, 2000. p. 63-74. 
REFLECTIONS ON THE AVAILABILITY OF HISTORICAL SOURCES IN CEMEDEF / UFPR

\begin{abstract}
This paper aims to present a reflection about the availability of historical sources in Memory Center of Physical Education, Department of Physical Education, Federal University of Paraná. Guided by the following questions: when can we make it accessible? How can we make it accessible? Who is going to access the sources? The research aimed to reflect on the role of these centers in the custody of the memory and fostering research. The general conclusion is that although these institutions are essential for the promotion of research in the areas of Social Sciences the effort in this case was "limited" and "limiting" but made no fiction, hype and all that life care imposes everyday who conducts historical research in Physical Education in Brazil.
\end{abstract}

Key-words: Memory Center; Physical Education; Historical Sources.

Recebido em: agosto/2013 Aprovado em: novembro/2013 